\title{
Analysis of Change of Event Related Potential in Escape Test using Virtual Reality Technology
}

\author{
Kyung-Yae Hyun ${ }^{1, *}$ and Gil-Hyun Lee ${ }^{2, ;, *}$ \\ ${ }^{I}$ Department of Clinical Laboratory Science, Dong-Eui University, Busan 47340, Korea \\ ${ }^{2}$ Department of Clinical Laboratory Science, Dong-Seo University, Busan 47011, Korea
}

\begin{abstract}
The role of electroencephalography (EEG) in the development of brain-computer interface (BCI) technology is increasing. In particular, the importance of the analysis of event related potential (ERP) in various situations is becoming more significant in BCI technology. Studies on past maze and fire situations have been difficult due to risks and realistic problems. Nowadays, according to the development of virtual reality (VR) technology, realistic maze and fire situation can be realized. In this study, ERPs (P300, and evented related negativity) were analyzed to collect objective data on case determination in an emergency situation. In order to overcome the limitations of previous methods that evaluating the EEG frequency change, ERPs were derived by setting epochs for stimulation and standardizing them, and evaluated for ERPs in this study. P3a and P3b, which are subcomponents of P300, were analyzed and the evented related negativity (ERN) was analyzed together with error positivity (Pe). As a result of the study, statistically significant changes of ERPs were observed, this result, which has little related research, is considered to be meaningful as medical basic statistics.
\end{abstract}

Key Words: Virtual reality, EEG, BCI, ERP, ERN, Pe, P300, P3a, P3b

\section{INTRODUCTION}

The concept of virtual reality (VR) is similar to reality but is an artificially-created environment. Devices that implement virtual reality are used as a means of giving users an experience taking place within simulated environments. Technologies of virtual reality have been developed since 1980 in earnest, and virtual reality devices are commercialized thanks to the development of input devices such as real-time 3D rendering, speech technology and motion capture (Chung et al., 2018; Spinelli et al., 2018). However, to realize fullyimmersive virtual reality that has not been implemented yet, brain-computer interface $(\mathrm{BCI})$ that processes inputs and outputs is required, but $\mathrm{BCI}$ technology has not been fully developed (Ricardo and Antonio, 2009). BCI needs to enable the brain of users not only to give orders to computers but also to read the messages of computers. In other words, two-way data communications between a computer and the brain should be realized. Some earlier studies succeeded in realizing inputs and outputs of motions and emotions to a limited extent, but the current level of BCI technologies have not reached to a level that can implement the original concept (Dan and Reiner, 2017; Berger and Davelaar, 2018). In addition, most of currently-developed BCI technologies employed non-invasive methods of detecting the brain waves

Received: June 10, 2019 / Revised: June 14, 2019 / Accepted: June 18, 2019

* Professor.

$\dagger$ Corresponding author: Gil-Hyun Lee. Department of Clinical Laboratory Science, Dong-Seo University, Busan 47011, Korea.

Tel: +82-51-890-2683, Fax: +82-0505-182-6877, e-mail: rokmagnum@naver.com

(C) The Korean Society for Biomedical Laboratory Sciences. All rights reserved.

(c) This is an Open Access article distributed under the terms of the Creative Commons Attribution Non-Commercial License (http://creativecommons.org/licenses/by-nc/3.0/) which permits unrestricted non-commercial use, distribution, and reproduction in any medium, provided the original work is properly cited. 
of users, and these technologies mostly detect and interpret output signals from the brain, which is one-way communications (Fabien et al., 2012). Recently, very few researchers reported that they succeeded in using brain waves of limited motions as an output signal, but technologies of inputting computer data into the brain have yet to be developed (Gert and Christa, 2006). As these facts show, analyzing and interpreting brain waves in a non-invasive manner are one of the essential elements for the development of BCI technologies, and multiple studies applied a variety of variables to subjects and attempted to measure changes in brain waves.

Several earlier studies analyzed and identify the relationship between humans' behaviors and brain waves (Pu et al., 2018), and reported that alpha $(\alpha)$ waves $(8 \sim 13 \mathrm{~Hz})$ are stable waves and that beta $(\beta)$ waves $(13 \sim 30 \mathrm{~Hz})$ are active waves. Theta $(\theta)(4 \sim 8 \mathrm{~Hz})$ and delta $(\delta)(0 \sim 4 \mathrm{~Hz})$ waves are known to show a decrease in the level of consciousness (Bischof and Boulanger, 2003; Cornwell et al., 2014). However, these waves do not exist individually, but instead multiple types of waves are overlapped momentarily. For this reason, brain waves observed in reality contain various components, and methods of quantitatively measuring how much each oscillating component in a certain range accounts for have been widely used. These research methods are used to examine the share of the band power in a certain range and changes in the share (Wamain et al., 2016; Chuang et al., 2016). Recent studies, however, tend to use an event related potential (ERP) to analyze brain waves in response to emotional changes in an urgent situation (Tarnanas et al., 2012; Spinelli et al., 2018). An ERP is defined as a change in potential that occurs in the brain against external stimuli or internal psychological processes (Nair et al., 2016). Various ERPs were discovered by researchers, and the P300 and errorrelated negativity (ERN) are noteworthy. The P300, one of intrinsic ERPs, was described by Chapman and Bragdon (1964), and has been most widely researched since then. The P300 is a positive (+) potential that occurs about $300 \mathrm{msec}$ after a stimulus is presented. The amplitude of the component increases as subjects' level of attention increases, and latency increases as the level of difficulty of the suggested stimulus increases (Lee and Lee, 2016). For this reason, the P300 provides an important lead to the cognitive process of a task. The
P300 can be divided into the novelty $\mathrm{P}$ (P3a) and the classic P300 (P3b) (Squires et al., 1975). The P3a is mostly observed in the frontal lobes and is known to be associated with attention to directional and environmental changes (Titlic et al., 2015). ERN is associated with the detection of errors, suppression, immediate correction and compensation for errors, and is a negative $(-)$ potential that is obtained by calculating the weighted average of brain waves responses to errors that subjects make with the same phase (Gehring, 1993; Gehring et al., 1993). The amplitude is about $10 \mu \mathrm{V}$, and it reached peaks about $150 \mathrm{msec}$ after the onset of electromyographic activity related to erroneous response. ERN reflects the detection of errors or the level of individuals' response to errors (Gehring et al., 1993; Dikman and Allen, 2000). After ERN occurs, error positivity $(\mathrm{Pe})$ at the peak that shows positive potential is observed near center and parietal electrodes for about 150 400 ms. ERN is known to occur right after subjects make an error during a task that causes errors, and the amplitude of ERN is very sensitive to subjects' intention or motive (Falkenstein et al., 1991; Luu et al., 2004). It tends to increase when subjects want to find a correct answer to a problem, instead of solving it quickly (Moon and Kim, 2018). Since the Pe and ERN are observed in different areas in the brain, the two seem to be independent, but the Pe is also associated with psychological responses to errors (Falkenstein et al., 2000). In particular, the Pe is known as an indicator that reflects the process of controlling errors. It increases right after subjects make an error or their errors become known, which supports the findings above. The amplitude of the Pe increases when subjects consciously make an attempt to control errors, and this indicates that the Pe is an ERP that occurs when subjects consciously try to reduce errors while ERN is a response that occurs when subjects simply perceive errors (Muller-Gass and Campbell, 2002; Pailing and Segalowitz, 2004).

In the past, it was difficult to conduct studies on extreme situations or those with risk factors such as fire, emergency escape and lifesaving due to economic and ethical issues caused to subjects. However, these constraints in reality can be overcome with VR technologies, and dangerous situations such as mazes and fires can be indirectly experienced through the technologies (Seiji and Satoshi, 2011). In this 
study, flickering arrows were marked on the floor to ensure subjects can see in smoke in the event of fire and quickly respond to the situation. This study was designed under the hypothesis that these arrows are effective in guiding subjects to escape the fire, and examined whether the existence of arrows was really helpful to reduce the time of escape (since the repeated experiments can make subjects accustomed to the place and find an exit more quickly) using ERPs as an assessment tool to objectively assess the utility of arrows in subway stations. Among ERPs, the P300 and ERN were measured and changes in the level of attention and responses to errors were interpreted. There has been no study that used VR technologies in the assessment of ERPs in Korea and overseas, and, in this regard, this study is meaningful as a basic clinical study on virtual reality of fire events.

\section{MATERIALS AND METHODS}

\section{Subjects}

This study was conducted among a total of 50 young adults (20 males, 30 females). Participants were fully informed about the procedure of the experiment before the experiment. Through a pre-survey questionnaire, those who had brain diseases, breathing disorders, claustrophobia, dizziness or tinnitus over the past 6 months were exclude from this experiment. This experiment was performed according to the research ethics of Dongeui University.

\section{Experimental design}

The following four environments are implemented using VR. 1) maze model without direction arrow (Pre-maze) 2) maze model with direction arrow (Post-maze) 3) subway fire model without direction arrow (Pre-subway) 4) subway fire model with direction arrow (Post-subway) All four environments have fixed starting positions and have a common goal to find the exit and escape. Also, all subjects have no information about maze and subway. The order of the experiment was the first day to see the reaction in an arrowless environment (Pre-maze, Pre-subway). After one week, we added the instruction arrow to the same environment and performed tests (Post-maze, Post-subway). The reason for the interval of one week was to reduce the fatigue of subject and the familiarity of place by continuous tests. The VR test space was set to $15 \times 10 \mathrm{~m}$, which is the maximum size that can be set by the device tool, and the VR experiment was performed after setting the start position vector information. VR experience was used with VR device (HTC VIVE Pro Virtual Reality Headset htc). According to a study by Seiji and Satoshi (2011), the similarity between virtual fire scene and real fire scene is proportional to the screen color and naturalness of screen motion. In this study, to improve the similarity with actual fire scene, VR headset with $1,440 \times$ 1,600 pixel and $90 \mathrm{~Hz}$ refresh frequency per eye was used to design the color and movement of the screen as close to reality as possible. The NVIDIA GeForce GTX 1060 GPU and Intel i7 dual core enable natural screen processing and smoothly process information.

\section{Electroencephalography (EEG)}

EEG measured eight channels based on the international 10 20 method. It was conducted in a laboratory equipped with insulation and soundproofing, and the impedance of each channel was kept below $5 \mathrm{~K} \Omega$. The active electrodes were $\mathrm{F}$ (Frontal $)_{3}, \mathrm{~F}_{4}, \mathrm{C}(\mathrm{Central})_{3}, \mathrm{C}_{4}, \mathrm{P}(\text { Parietal })_{3}, \mathrm{P}_{4}, \mathrm{O}_{1}$ (Occipital), $\mathrm{O}_{2}$. When the EEG measured at all electrodes exceeded $\pm 100 \mu \mathrm{V}$, they were regarded as artifacts and removed without being included in final analysis. The EEG of subjects was measured using an EEG headset called Quick-20 (Pelican products Torrance CA, USA).

\section{EEG data extraction and analysis}

The relative power ratio of $\alpha$ wave and $\beta$ wave were analyzed for total measured time. The analysis of relative power ratio between $\alpha$ and $\beta$ waves was performed using occipital and frontal electrodes, which generate the clearest waveforms. Lee and Lee (2016) and Cattan et al. (2018)'s methods for evaluating ERP according to successive tasks was modified. In the labyrinth experiment, the choice of branching through visuals and the gazing of direction arrow were set as the check point where the stimulation occurred. In the subway experiment, check point was set as entry, exit, door movement, corner movement, step movement, direction change, and gazing direction arrow. Each check point is a visual stimulus to induce ERP. Sampling was performed by 
Table 1. Results for escape time and epoch analysis

\begin{tabular}{lccccc}
\hline \hline \multicolumn{1}{c}{ Group } & Escape time (sec) & P300 Epoch sampling (n) & ERN Epoch sampling (n) & $t$ & $P$ \\
\hline Pre-maze & $84.01(20.27)$ & $66.61(12.65)$ & $55.32(14.65)$ & 9.64 & 0.00 \\
Post-maze & $56.26(17.98)$ & $53.04(9.28)$ & $45.24(12.09)$ & $43.29(10.57)$ & \multirow{2}{*}{9.47} \\
\hline Pre-subway & $77.44(15.11)$ & $50.49(9.35)$ & $38.58(7.62)$ & 0.00 \\
Post-subway & $51.92(13.16)$ & $41.56(6.92)$ & & \\
\hline
\end{tabular}

( ) standard deviation, $P$; comparison between the difference between escape time of pre groups and it of post groups

cutting and collecting epochs of required length according to ERP type based on stimulus. The ERP waveforms were generated by using the average addition method for at least 30 epochs. The similarities of negative peak, positive peak, and latency with the existing ERP waveform were compared. If the waveforms have completely different waveforms or if the difference between the values of sampling elements and classical ERP elements are two times or more different from each other, the waveforms are discarded and the similar type of ERP waveforms are derived as much as possible through epoch sampling repetition (Zhu et al., 2017; Somon et al., 2019). First, for the analysis of ERN, EEGs were extracted for 0.8 second within 0.3 seconds and 0.5 seconds before and after each checkpoint. Digital filtering was performed with $0.1 \sim 60 \mathrm{~Hz}$ bandpass in 8 channels. Average ERNs were generated by using the averaging method on epochs collected from $\mathrm{P}_{3}, \mathrm{P}_{4}, \mathrm{C}_{3}$, and $\mathrm{C}_{4}$ electrodes. To determining the average ERN amplitude for an individual involves calculating the peak-to-peak difference in voltage between the average of the most negative peaks $1 \sim 150 \mathrm{~ms}$ after response onset, and the average amplitude of positive peaks 0 100 ms before response onset (Gentsch et al., 2009). For the analysis of P300, EEGs were extracted for 1.1 second within 0.1 seconds and 1 seconds before and after each checkpoint. The P3a has a positive-going amplitude that displays maximum amplitude over frontal/central electrode sites and has a peak latency in the range of $250 \sim 280 \mathrm{~ms}$. The P3b has a positive-going amplitude that peaks at around $300 \mathrm{~ms}$, and the peak will vary in latency from 250 500 ms. Amplitudes are typically highest on the scalp over parietal brain areas. The amplitude of P300 was measured by the peak-peak method. The difference between the P300 peak potential and the negative peak potential value after P300 was defined as the amplitude of P300 (Rohani et al., 2014). The potential of negative peak is the smallest value of $100 \mathrm{~ms}$ after P300. Extraction of P3a and P3b, the subcomponents of P300, were extracted using special topographic distributions with maximum amplitude at the central and parietal electrodes. Power spectral analysis and ERP analysis were performed using the Cognionics Data acquisition program (LAXTHA inc. USA) and the BrainMap-3D program (LAXTHA inc. USA).

\section{Statistical processing}

The comparison between the variables in the pre and post groups was made using paired $t$-test. Statistical analysis was performed by nonparametric method if normality was not satisfied after normality test of each variable. Comparisons between the electrodes were compared using ANOVA. When there is a significant difference between the groups, Turkey's post-hoc method is used. SPSS 20.0 program for windows was used for all analyzes.

\section{RESULTS}

\section{Escape time and epoch analysis}

There was a statistically significant difference in escape time between the post group and the pre group (Table 1). Table 1 shows the number of epochs showing typical results among extracted epochs for stimulus. The epoch extraction of P300 and ERN was adopted only when a typical ERP waveform was shown through repeated extraction of each step.

\section{Relative power ratio}

Relative power ratios were calculated for eight regions 
(data not shown). Relative power ratios of $\alpha$ wave and $\beta$ wave, where relative waves are the most vivid and predominant, were calculated in the occipital area and frontal electrodes. The relative power ratios of the $\alpha$ waves measured at the occipital area were significantly higher in the post group (subway: $\mathrm{O}_{1}=0.14 \pm 0.03, \mathrm{O}_{2}=0.08 \pm 0.02$, maze: $\mathrm{O}_{1}=0.21 \pm 0.06, \mathrm{O}_{2}=0.16 \pm 0.04$, maze: $\mathrm{O}_{1}=0.23 \pm$ $\left.0.05, \mathrm{O}_{2}=0.17 \pm 0.03\right)(P<0.01)$. On the other hand, the ratio of relative $\beta$ waves measured at the frontal region was significantly lower in the post groups than in the pre groups $(P<0.05)$.

\section{Mean amplitude and latency of event related potential (ERP)}

P300 and ERN epochs were extracted from different waveforms. $\mathrm{P} 300$ is classified into $\mathrm{P} 3 \mathrm{a}$ and $\mathrm{P} 3 \mathrm{~b}$, and the results are shown in Table 2. Comparing the pre groups (premaze and pre-subway) and post groups (post-maze and post-

Table 2. Mean P3a and P3b latency and amplitude values for experimental groups

\begin{tabular}{|c|c|c|c|c|c|c|c|c|c|}
\hline \multirow{2}{*}{ Component } & \multirow{2}{*}{$\begin{array}{l}\text { Electrode } \\
\text { site }\end{array}$} & \multicolumn{2}{|c|}{$\begin{array}{c}\text { Pre-Maze } \\
\text { group }(n=50)\end{array}$} & \multicolumn{2}{|c|}{$\begin{array}{c}\text { Post-Maze } \\
\text { group }(n=50)\end{array}$} & \multicolumn{2}{|c|}{$\begin{array}{l}\text { Pre-Subway } \\
\text { group }(n=50)\end{array}$} & \multicolumn{2}{|c|}{$\begin{array}{l}\text { Post-Subway } \\
\text { group }(n=50)\end{array}$} \\
\hline & & $\begin{array}{l}\text { Amplitude } \\
(\mu \mathrm{V})\end{array}$ & $\begin{array}{l}\text { Latency } \\
(\mathrm{msec})\end{array}$ & $\begin{array}{l}\text { Amplitude } \\
(\mu \mathrm{V})\end{array}$ & $\begin{array}{c}\text { Latency } \\
\text { (msec) }\end{array}$ & $\begin{array}{l}\text { Amplitude } \\
(\mu \mathrm{V})\end{array}$ & $\begin{array}{c}\text { Latency } \\
\text { (msec) }\end{array}$ & $\begin{array}{l}\text { Amplitude } \\
(\mu \mathrm{V})\end{array}$ & $\begin{array}{l}\text { Latency } \\
\text { (msec) }\end{array}$ \\
\hline \multirow[t]{2}{*}{$\mathrm{P} 3 \mathrm{a}$} & $\mathrm{C}_{3}$ & $\begin{array}{l}15.68 \\
(9.08)\end{array}$ & $\begin{array}{l}387.59 \\
(55.09)\end{array}$ & $\begin{array}{l}11.08 \\
(4.80)\end{array}$ & $\begin{array}{l}339.02 \\
(40.01)\end{array}$ & $\begin{array}{l}28.06 \\
(7.40)\end{array}$ & $\begin{array}{l}470.22 \\
(42.70)\end{array}$ & $\begin{array}{l}20.42 \\
(6.11)\end{array}$ & $\begin{array}{l}370.12 \\
(32.68)\end{array}$ \\
\hline & $\mathrm{C}_{4}$ & $\begin{array}{l}14.89 \\
(8.72)\end{array}$ & $\begin{array}{l}398.28 \\
(59.30)\end{array}$ & $\begin{array}{l}12.25 \\
(5.01)\end{array}$ & $\begin{array}{l}328.77 \\
(41.50)\end{array}$ & $\begin{array}{l}27.19 \\
(8.08)\end{array}$ & $\begin{array}{l}483.33 \\
(39.28)\end{array}$ & $\begin{array}{l}22.78 \\
(5.52)\end{array}$ & $\begin{array}{l}351.74 \\
(43.82)\end{array}$ \\
\hline \multirow[t]{2}{*}{ P3b } & $\mathrm{P}_{3}$ & $\begin{array}{l}10.25 \\
(4.41)\end{array}$ & $\begin{array}{l}361.20 \\
(41.40)\end{array}$ & $\begin{array}{l}12.10 \\
(6.11)\end{array}$ & $\begin{array}{l}324.81 \\
(40.37)\end{array}$ & $\begin{array}{l}14.71 \\
(7.66)\end{array}$ & $\begin{array}{l}450.46 \\
(47.69)\end{array}$ & $\begin{array}{c}18.77 \\
(10.54)\end{array}$ & $\begin{array}{l}358.08 \\
(42.76)\end{array}$ \\
\hline & $\mathrm{P}_{4}$ & $\begin{array}{l}11.52 \\
(5.37)\end{array}$ & $\begin{array}{l}370.24 \\
(33.00)\end{array}$ & $\begin{array}{l}12.69 \\
(4.83)\end{array}$ & $\begin{array}{l}312.04 \\
(29.71)\end{array}$ & $\begin{array}{l}15.18 \\
(6.40)\end{array}$ & $\begin{array}{l}461.80 \\
(46.06)\end{array}$ & $\begin{array}{l}18.06 \\
(7.02)\end{array}$ & $\begin{array}{l}370.11 \\
(49.16)\end{array}$ \\
\hline
\end{tabular}

( ) standard deviation

Table 3. Mean amplitude and latency of ERN and Pe for experimental groups

\begin{tabular}{|c|c|c|c|c|c|c|c|c|c|}
\hline \multirow{2}{*}{ Component } & \multirow{2}{*}{$\begin{array}{l}\text { Electrode } \\
\text { site }\end{array}$} & \multicolumn{2}{|c|}{$\begin{array}{c}\text { Pre-Maze } \\
\text { group }(n=50)\end{array}$} & \multicolumn{2}{|c|}{$\begin{array}{c}\text { Post-Maze } \\
\text { group }(n=50)\end{array}$} & \multicolumn{2}{|c|}{$\begin{array}{l}\text { Pre-Subway } \\
\text { group }(n=50)\end{array}$} & \multicolumn{2}{|c|}{$\begin{array}{l}\text { Post-Subway } \\
\text { group }(n=50)\end{array}$} \\
\hline & & $\begin{array}{l}\text { Amplitude } \\
(\mu \mathrm{V})\end{array}$ & $\begin{array}{c}\text { Latency } \\
\text { (msec) }\end{array}$ & $\begin{array}{l}\text { Amplitude } \\
(\mu \mathrm{V})\end{array}$ & $\begin{array}{l}\text { Latency } \\
\text { (msec) }\end{array}$ & $\begin{array}{l}\text { Amplitude } \\
(\mu \mathrm{V})\end{array}$ & $\begin{array}{l}\text { Latency } \\
\text { (msec) }\end{array}$ & $\begin{array}{l}\text { Amplitude } \\
(\mu \mathrm{V})\end{array}$ & $\begin{array}{c}\text { Latency } \\
(\mathrm{msec})\end{array}$ \\
\hline \multirow[t]{4}{*}{ ERN } & $\mathrm{F}_{3}$ & $\begin{array}{l}-4.31 \\
(2.02)\end{array}$ & $\begin{array}{c}90.88 \\
(29.45)\end{array}$ & $\begin{array}{l}-3.01 \\
(2.63)\end{array}$ & $\begin{array}{c}91.01 \\
(33.15)\end{array}$ & $\begin{array}{l}-1.58 \\
(2.50)\end{array}$ & $\begin{array}{c}87.62 \\
(25.83)\end{array}$ & $\begin{array}{l}-8.25 \\
(3.81)\end{array}$ & $\begin{array}{c}89.97 \\
(29.35)\end{array}$ \\
\hline & $\mathrm{F}_{4}$ & $\begin{array}{l}-4.90 \\
(2.45)\end{array}$ & $\begin{array}{c}91.60 \\
(31.00)\end{array}$ & $\begin{array}{l}-3.48 \\
(1.95)\end{array}$ & $\begin{array}{c}90.48 \\
(28.49)\end{array}$ & $\begin{array}{l}-2.52 \\
(3.17)\end{array}$ & $\begin{array}{c}89.68 \\
(33.42)\end{array}$ & $\begin{array}{l}-8.99 \\
(3.30)\end{array}$ & $\begin{array}{c}90.68 \\
(29.52)\end{array}$ \\
\hline & $\mathrm{C}_{3}$ & $\begin{array}{l}-6.25 \\
(4.12)\end{array}$ & $\begin{array}{c}91.60 \\
(31.58)\end{array}$ & $\begin{array}{l}-4.53 \\
(2.53)\end{array}$ & $\begin{array}{c}92.98 \\
(30.41)\end{array}$ & $\begin{array}{l}-3.69 \\
(4.06)\end{array}$ & $\begin{array}{c}91.66 \\
(29.14)\end{array}$ & $\begin{array}{l}-11.03 \\
(4.61)\end{array}$ & $\begin{array}{c}92.66 \\
(32.73)\end{array}$ \\
\hline & $\mathrm{C}_{4}$ & $\begin{array}{l}-6.52 \\
(4.48) \\
\end{array}$ & $\begin{array}{c}92.09 \\
(38.12) \\
\end{array}$ & $\begin{array}{l}-4.77 \\
(1.59) \\
\end{array}$ & $\begin{array}{c}90.90 \\
(34.36)\end{array}$ & $\begin{array}{l}-4.28 \\
(3.70)\end{array}$ & $\begin{array}{c}90.87 \\
(32.52) \\
\end{array}$ & $\begin{array}{l}-13.77 \\
(5.09) \\
\end{array}$ & $\begin{array}{c}88.90 \\
(32.11) \\
\end{array}$ \\
\hline \multirow[t]{4}{*}{$\mathrm{Pe}$} & $\mathrm{C}_{3}$ & $\begin{array}{l}2.65 \\
(2.17)\end{array}$ & $\begin{array}{l}188.03 \\
(31.02)\end{array}$ & $\begin{array}{l}5.89 \\
(2.36)\end{array}$ & $\begin{array}{l}126.20 \\
(33.64)\end{array}$ & $\begin{array}{c}1.81 \\
(2.33)\end{array}$ & $\begin{array}{l}189.98 \\
(33.51)\end{array}$ & $\begin{array}{c}7.28 \\
(3.82)\end{array}$ & $\begin{array}{l}192.18 \\
(30.50)\end{array}$ \\
\hline & $\mathrm{C}_{4}$ & $\begin{array}{c}2.90 \\
(2.32)\end{array}$ & $\begin{array}{l}187.62 \\
(28.10)\end{array}$ & $\begin{array}{c}6.17 \\
(2.89)\end{array}$ & $\begin{array}{l}189.58 \\
(39.09)\end{array}$ & $\begin{array}{l}1.76 \\
(2.04)\end{array}$ & $\begin{array}{l}191.55 \\
(30.72)\end{array}$ & $\begin{array}{c}7.83 \\
(3.32)\end{array}$ & $\begin{array}{l}189.94 \\
(29.87)\end{array}$ \\
\hline & $\mathrm{P}_{3}$ & $\begin{array}{c}1.32 \\
(1.80)\end{array}$ & $\begin{array}{l}190.21 \\
(36.23)\end{array}$ & $\begin{array}{c}5.28 \\
(1.51)\end{array}$ & $\begin{array}{l}193.50 \\
(35.08)\end{array}$ & $\begin{array}{c}1.55 \\
(1.99)\end{array}$ & $\begin{array}{l}189.60 \\
(31.58)\end{array}$ & $\begin{array}{c}5.63 \\
(2.12)\end{array}$ & $\begin{array}{l}191.08 \\
(31.58)\end{array}$ \\
\hline & $\mathrm{P}_{4}$ & $\begin{array}{c}1.48 \\
(1.59)\end{array}$ & $\begin{array}{c}188.38 \\
(34.76)\end{array}$ & $\begin{array}{c}4.56 \\
(1.70)\end{array}$ & $\begin{array}{l}189.68 \\
(32.80)\end{array}$ & $\begin{array}{c}1.40 \\
(2.62)\end{array}$ & $\begin{array}{l}189.37 \\
(31.60)\end{array}$ & $\begin{array}{c}4.99 \\
(2.69)\end{array}$ & $\begin{array}{c}192.33 \\
(30.87)\end{array}$ \\
\hline
\end{tabular}

( ) standard deviation 

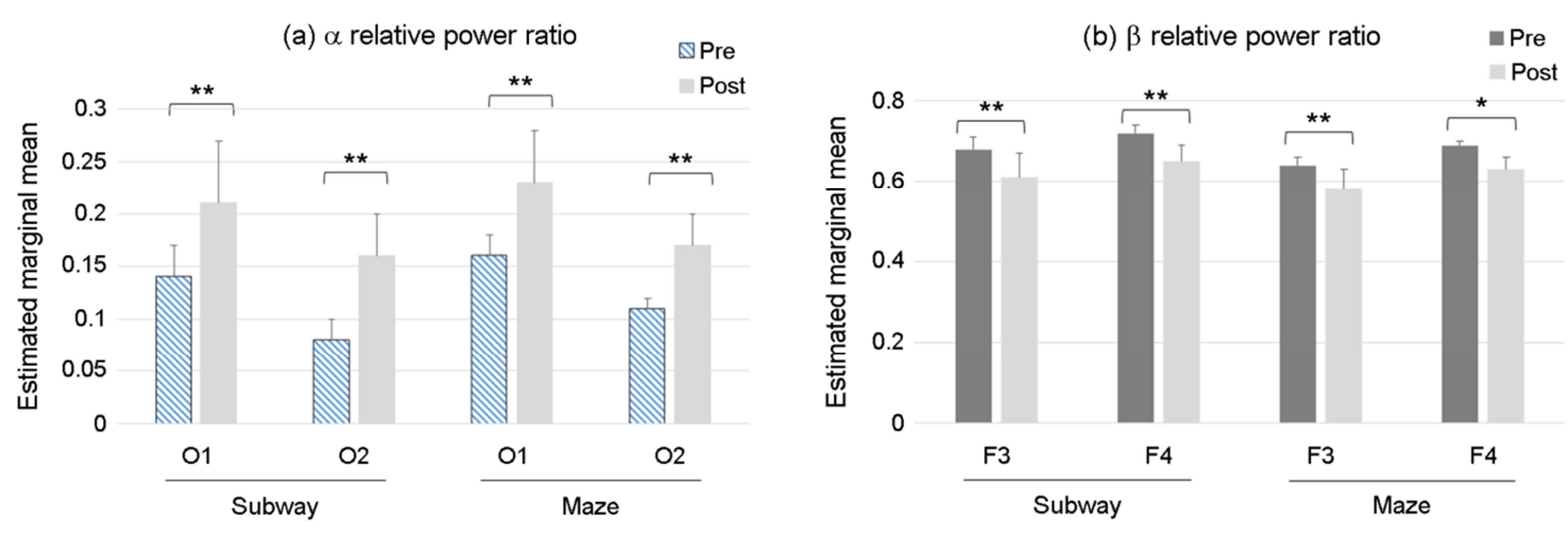

Fig. 1. Results for relative power ratio of EEG. (a) Result of $\alpha$ wave relative power ratio, (b) Result of $\beta$ wave relative power ratio. The $\alpha$ and $\beta$ waves were analyzed using the occipital area and the frontal area where each wave was clearly observed. Compared with the group without the direction arrow (pre groups), the $\alpha$ wave increased and the $\beta$ wave tended to decrease in the group with the pointing arrow (post groups) $(* * ; P<0.01, * ; P<0.05)$.

subway), the amplitude of the post groups was statistically significantly lower $(P<0.05)$ in $\mathrm{C}_{3}$ and $\mathrm{C}_{4}$. On the other hand, in $\mathrm{P} 3 \mathrm{~b}$, the amplitudes were increased in the post groups compared to the pre-groups and the statistically significant differences were in the pre-subway and post-subway groups $(P<0.05)$. The latency of $\mathrm{P} 3 \mathrm{a}$ and $\mathrm{P} 3 \mathrm{~b}$ was found to be shorter in the post group than in the pre-group in all electrode sites $(P<0.01)$. In comparison of pre-maze and presubway, there was statistically significant difference between amplitude and latency of the two groups $(P<0.01)$. ERN was measured using EEG measured at $\mathrm{F}_{3}, \mathrm{~F}_{4}, \mathrm{C}_{3}$, and $\mathrm{C}_{4}$ electrodes, and Pe was analyzed using EEGs measured at $\mathrm{C}_{3}, \mathrm{C}_{4}, \mathrm{P}_{3}$, and $\mathrm{P}_{4}$ electrodes. Table 3 shows that there was a statistically significant difference between the amplitude and latency of the pre and post groups $(P<0.05)$. Comparing the pre groups and the post groups, the absolute value of ERN amplitude in the maze group was reduced while the absolute value of ERN amplitude in the subway group was increased $(P<0.05)$. And, there was a significant difference in the pre and post groups of Pe amplitudes $(P<0.05)$. However, unlike ERN amplitude, Pe amplitude tended to increase in the post groups compared to the pre groups $(P$ $<0.05)$. The latency of Pe was significantly decreased in the post groups compared to the pre groups at all electrodes $(P<0.01)$.

\section{DISCUSSION}

This study conducted an escape task based on the ratio of brain wave to band power, ERN and P300, and compared the physiological and psychological responses of subjects to identify significant differences. The average age of subjects was $23.63 \pm 3.52$ years, and variables related to virtual events of fires such as diseases and experience of fires were controlled to reduce errors caused by the characteristics of individuals. At Fig. 1, The process of analyzing the results of this experiment focused on the power that each frequency band has. Since changes in the absolute power of brain waves did not seem to be suitable to analyze brain waves related to psychological processes, the ratio of $\alpha$ and $\beta$ waves to relative band power that can noticeably reflect changes in bands was used in this study. The ratio of band power in a tranquil moment was replaced with the results of earlier studies, but since they were far from the results of this study, they were not listed here. According to relevant studies (Wang et al., 2015; Berger and Davelaar, 2018), the relative power of $\alpha$ waves increases when the functions of the brain are relaxed or stabilized, while it significantly decreases when tasks are complicated and difficult. The relative power of $\beta$ waves tends to increase in the frontal lobes while performing tasks instead of the stable state (Wang et al., 2015). In this study, the relative power of $\alpha$ waves that occurs in the occip- 
ital lobes and the relative power of $\beta$ waves that occurs in the frontal lobes were compared during an escape task. The results of this study showed that the relative power of $\alpha$ waves increased in both the two experimental models, which indicates that the existence of directional arrows gave the sense of stability to subjects. Meanwhile, the relative power of $\beta$ waves decreased in both the two experimental models, and the results indicate that directional arrows might reduce the level of difficulty of the escape task. However, since analyzing the ratio of relative power to brain waves is used to examine the psychological mood of subjects instead of their responses to tasks, it is not sufficient enough to assess whether the solution was effective or not. For this reason, the experimental models were assessed through ERP brain waveform analysis that was modified in a more quantitative manner.

ERPs are electrical changes caused by external stimuli or internal psychological processes, and their temporal resolution is the highest among imaging techniques used to research the functions of the brain (Falkenstein et al., 2000). ERPs can be divided into extrinsic ERPs of which waveforms are determined by external stimuli and intrinsic ERPs of which waveforms are determined in internal cognitive processes regardless of stimuli (Nair et al., 2016). The P300, one of ERPs, is an intrinsic ERP that is associated with cognitive functions and occurs regardless of presented stimuli (Chen et al., 2014). However, since there is a little difference between the P300 of auditory stimuli and the P300 of visual stimuli (Chen et al., 2014), this study directly extracted brain wave epochs during which behavioral changes associated with eyesight were observed in order to extract ERPs that are induced only by visual stimuli. General ERPs are obtained by calculating the weighted average of epochs caused by repetitive standardized behaviors. The reproducibility and reliability of these ERPs are very high. In this study, the ERP extraction method during consecutive tasks developed by Lee and Lee (2016) and Cattan et al. (2018) was modified. Since visual stimuli are not in a standardized form, the shape, latency time and amplitude of ERP waveforms were compared with standardized ERP curves. If the difference is more than two times higher than the average value, the ERP curve was discarded and epochs were sampled again to induce ERP curves and thus to improve their reproducibility and accuracy.

Studies on the P300 mostly use an 'oddball' model that presents two stimuli randomly and respond to target stimuli that infrequently occur (Polich and Margala, 1997), and this study was conducted under the hypothesis that directional arrows presented between visual stimuli at crossroads play a role as a target stimulus. According to the P300 amplitude determination model suggested by Rohani et al. (2014), the amplitude of the P300 is obtained using the following equation. $\mathrm{P} 300(\mathrm{P} 3 \mathrm{~b})$ amplitude $=$ flTX $(\mathrm{l} / \mathrm{P}+\mathrm{M})]$, $\mathrm{P}$ : subjective probability, M: stimulus meaning, T: information transmission. Here, subjective probability is a probability in which individual judgements are involved, and the lower the subjective probability, the higher the amplitude of the P300, which indicates that the amplitude of the $\mathrm{P} 3 \mathrm{~b}$ is inversely proportional to the level of uncertainty (Comerchero and Polich, 1999). The amplitude of the P $3 b$ tends to increase during complicated tasks compared to simple tasks (Comerchero and Polich, 1999; Yuezhi et al., 2015). In addition, it is inevitable to lose data in the process of transferring data, and the amplitude of the P3b is higher when stimuli are clear than when they are vague. As shown in Table. 2, there was no significant difference in the amplitude of the P300 (P3b) between the pre-maze and post-maze models, which can be indirect evidence that the maze environments failed to induce motives that can increase the attention of subjects. The significance difference in the latency of the P3b between the maze environments seems to indicate that directional arrows were helpful to make decisions on navigation as the escape time decreased as shown in Table 1. The results of the subway fire model were interesting compared to those of the maze model. The amplitude of the pre-maze and pre-subway models was compared, and there was a significant increase, which can be interpreted that the attention of subjects in the pre-subway model greatly increased. There was also a statistically significant difference between the amplitude of the pre-subway and post-subway models, which indicates that directional arrows not only simply reduced the escape time, but also played a role as a tool to increase attention that is required to handle situations. As the results of the maze model show, the latency significantly decreased in the subway model. In general, the amplitude of the P3b can be inter- 
preted as lack of attention due to vague data, but an increase in the amplitude in the post-subway model does not seem to be the result of vague data, but seems to be caused by an increase in attention by induced motives, and a decrease in subjective judgements. As Table 2 shows, the results of the P3a in this study, similar to those of earlier studies, showed a typical waveform that has the highest amplitude detected by the central electrode. The P3a is a waveform that responses to novelty stimuli and is associated with attention affected by directional and environmental changes. One thing interesting in these results is that the amplitude increased more significantly in the subway model than the maze model, which can be attributed to the distinct characteristics of the subway model and high tension in the special situation in which subjects started their task in a disoriented state compared to the maze model that has clear crossroads. Both the two models showed a significant decrease in the latency of the $\mathrm{P} 3 \mathrm{a}$ in their post model compared to their pre model, which also indicates a decrease in the escape time of subjects.

Studies that monitored behaviors using ERPs consistently reported ERN as an ERP associated with errors (Zhenhe et al., 2013; Taylor et al., 2018). The origin of ERN and Pe was also found to be the anterior cingulate cortex using source localization and brain imaging techniques (Zhenhe et al., 2013; Yuezhi et al., 2015). Standardized tools like the Simon Task (Masaki et al., 2007) are commonly used to measure $\mathrm{ERN}$, and in this study, sections where the grounds for judgements and behaviors occurred in the models were directly extracted to create epochs for the sections. Studies that monitored behaviors of those with anxiety disorders using ERPs (Yuezhi et al., 2015; Moon and Kim, 2018) reported that the group of those with anxiety disorders showed a significant increase in the amplitude of ERN compared to the control group. These studies implicate that those with high anxiety showed sensitive responses to errors (Yuezhi et al., 2015; Moon and Kim, 2018). Other studies reported that when the amplitude of ERN was big and latency was short, errors were less frequently observed and the time of responses was short, and that when subjects made errors, higher ERN was observed (Weschke and Niedeggen, 2016; Taylor et al., 2018). In particular, since ERN is not affected by senses (hearing, sight, etc.) or execution organs (hands, feet, etc.) but response only to the results of responses to tasks, the reliability of the results is higher than earlier studies that were conducted from the perspective of band power. As discussed above, the Pe is an ERP that occurs when people try to consciously reduce errors and increases when people consciously make efforts to control errors (Muller-Gass and Campbell, 2002; Pailing and Segalowitz, 2004). The ERN results observed in the maze and subway models (Table 3 ) showed that the amplitude of ERN in the post model of the two models increased compared to the pre model of the two models. These results can be interpreted from two aspects. First, in the model that directional arrows were not presented to subjects, it was difficult for them to perceive that their judgement itself was an error, which reduced the occurrence of ERN itself. On the other hand, in the post model that directional arrows were presented, directional arrows served as the grounds for judgements, which seemed to increase the perception of errors. Second, since there was no ground for determining truth in the Pre model, subjects seemed to be determined to solve escape tasks more quickly. In the post model, however, as directional arrows were presented, subjects seemed to try to solve the tasks more accurately based on the presented arrows instead of focusing on the speed of solving the escape tasks. Both the two interpretations indicate that directional arrows were effective in reducing confusion that subjects might experience during escape missions. The results coincided with those of the Pe. The amplitude of the Pe in the post model statistically significantly increased from the level in the Pre model, which indicates that subjects tried to control errors more consciously.

This study attempted to introduce new physiological indicators in order to assess the clinical and physiological effects of directional arrows in an escape experiment, to input a task and to interpret obtained results. Since there was no study on these irregular and consecutive situations, it was difficult to select epochs and interpret results, but typical ERPs were successfully extracted by repeating and correcting sample extractions. It was also possible to interpret how the existence of directional arrows worked in the maze and subway models from a new perspective, and the results can be applied to similar escape models and psychological and learning models as well. It is still necessary to increase the reliability 
of the tool used in this study and the results by repeating ERP experiments in various situations in follow-up studies. This study has a significance as a pilot research on the use of ERPs considering that it is difficult in reality to quantitatively assess the utility of tools (directional arrows, announcements, etc.) that can help people properly respond to emergency situations.

\section{ACKNOWLEDGEMENT}

This research was supported by the National Research Foundation of Korea (NRF) funded by the Ministry of Science, ICT \& Future Planning (NRF-2017R1C1B5076959).

\section{CONFLICT OF INTEREST}

No potential conflict of interest relevant to this article was reported.

\section{REFERENCES}

Berger AM, Davelaar EJ, Frontal Alpha Oscillations and Attentional Control: A Virtual Reality Neurofeedback Study. Neuroscience. 2018. 378: 189-197.

Bischof WF, Boulanger P. Spatial navigation in virtual reality environments: an EEG analysis. Cyberpsychol Behav. 2003. 6: 487-495.

Cattan G, Mendoza C, Andreev A, Congedo M. Recommendations for integrating a P300-based brain computer interface in virtual reality environments for gaming. Computers. 2018. 7: 34 .

Chapman RM, Bragdon HR. "Evoked responses to numerical and non-numerical visual stimuli while problem solving". Nature. 1964. 203: 1155-1157.

Chen CC, Syue KS, Li KC, Yeh SC. Neuronal correlates of a virtual-reality-based passive sensory P300 network. PLoS One. 2014. 17: 9.

Chuang SW, Chuang CH, Yu YH, King JT, Lin CT. EEG Alpha and Gamma Modulators Mediate Motion Sickness-Related Spectral Responses. Int J Neural Syst. 2016. 26: 1650007.

Chung K, Lee D, Park JY. J Med Internet Res. Nvoluntary Attention Restoration During Exposure to Mobile-Based $360^{\circ}$ Virtual Nature in Healthy Adults with Different Levels of Restorative Experience: Event-Related Potential Study. 2018. 20: e11152.
Comerchero MD, Polich J. "P3a and P3b from typical auditory and visual stimuli" (PDF). Clinical Neurophysiology. 1999. 110: 24-30.

Cornwell BR, Overstreet C, Grillon C. Spontaneous fast gamma activity in the septal hippocampal region correlates with spatial learning in humans. Behav Brain Res. 2014. 261: 258-264.

Dan A, Reiner M. EEG-based cognitive load of processing events in $3 \mathrm{D}$ virtual worlds is lower than processing events in $2 \mathrm{D}$ displays. Int J Psychophysiol. 2017. 122: 75-84.

Dikman ZV, Allen JJ. "Error monitoring during reward and avoidance learning in high- and low-socialized individuals". Psychophysiology. 2000. 37: 43-54.

Fabien L, Josef F, Christoph G, Yann R, Gert P, Anatole L, Robert L. Combining BCI with Virtual Reality: Towards New Applications and Improved BCI. Towards Practical Brain-Computer Interfaces 2012. pp 197-220.

Falkenstein M, Hohnsbein J, Hoormann J, Blanke L. Effects of crossmodal divided attention on late ERP components. I. Simple and choice reaction tasks. Electroencephalography and Clinical Neurophysiolgy. 1991. 78: 438-446.

Falkenstein M, Hoormann J, Christ S, Hohnsbein J. "ERP components on reaction errors and their functional significance: a tutorial". Biological Psychology. 2000. 51: 87-107.

Gehring WJ. The error-related negativity: Evidence for a neural mechanism for error-related processing (Ph.D. thesis). University of Illinois at Urbana-Champaign. 1993.

Gehring WJ, Goss B, Coles MG, Meyer DE. "A neural system for error detection and compensation". Psychological Science. 1993. 4: 385-390.

Gentsch A, Ullsperger P, Ullsperger M. "Dissociable medial frontal negativities from a common monitoring system for self- and externally caused failure of goal achievement". NeuroImage. 2009. 47: 2023-2030.

Gert P, Christa N. Future prospects of ERD/ERS in the context of brain-computer interface (BCI) developments. Progress in Brain Research. 2006. 159: 433-437.

Lee KW, Lee HW. Difference in P300 latency by levels of involvement to sport: Interdisciplinary approach to sport consumer behavior using embodied cognition theory and EEG/ERP technique. Korean Journal of Sport Management. 2016. 21: 45-56.

Luu P, Tucker DM, Makeig S. Frontal midline theta and the errorrelated negativity: neurophysiological mechanisms of action regulation. Clinical Neurophysiology. 2004. 115: 1821-1835.

Masaki H, Falkenstein M, Stürmer B, Pinkpank T, Sommer W. 
Does the error negativity reflect response conflict strength? Evidence from a Simon task. Psychophysiology. 2007. 44: 579-585.

Moon SH, Kim MS. An event-related potential study of action monitoring in female college students with high trait anxiety. The Korean Journal of Cognitive and Biological Psychology. 2018. 7: 225-240.

Muller-Gass A, Campbell K. Event-related potential measures of the inhibition of information processing: I. Selective attention in the waking state. Int J Psychophysiol. 2002. 46: 177-195.

Nair AK, Sasidharan A, John JP, Mehrotra S, Kutty BM. Assessing Neurocognition via Gamified Experimental Logic: A Novel Approach to Simultaneous Acquisition of Multiple ERPs. Front Neurosci. 2016. 10: 1.

Pailing PE, Segalowitz SJ. The error-related negativity as a state and trait measure: Motivation, personality, and ERPs in response to errors. Psychophysiology. 2004. 41: 84-95.

Polich J, Margala C. P300 and probability: comparison of oddball and single-stimulus paradigms. Int J Psychophysiol. 1997. 25: 169-176.

Pu Y, Cornwell BR, Cheyne D, Johnson BW. High-gamma activity in the human hippocampus and parahippocampus during intertrial rest periods of a virtual navigation task. Neuroimage. 2018. 178: 92-103.

Ricardo RA, Antonio DE. Brain-computer interface: Changes in performance using virtual reality techniques. Neuroscience Letters. 2009. 449: 123-127.

Rohani DA, Sorensen HB, Puthusserypady S. Brain-computer interface using P300 and virtual reality: a gaming approach for treating ADHD. Conf Proc IEEE Eng Med Biol Soc. 2014. 2014: 3606-3609.

Seiji T, Satoshi S. The psychophysioligical effects of the fireplace. Psychologia. 2011. 54: 68-79.

Somon B, Campagne A, Delorme A, Berberian B. Evaluation of performance monitoring ERPs through difficulty manipulation in a response-feedback paradigm. Brain Res. 2019. 1704: 196 $-206$.

Spinelli G, Tieri G, Pavone EF, Aglioti SM. Wronger than wrong: Graded mapping of the errors of an avatar in the performance monitoring system of the onlooker. Neuroimage. 2018. 167: 1-10.

Squires NK, Squires KC, Hillyard SA. "Two varieties of longlatency positive waves evoked by unpredictable auditory stimuli in man". Electroencephalography and Clinical Neurophysiology. 1975. 38: 387-401.

Tarnanas I, Laskaris N, Tsolaki M. On the comparison of VRresponses, as performance measures in prospective memory, with auditory P300 responses in MCI detection. Stud Health Technol Inform. 2012. 181: 156-161.

Taylor JB, Visser TA, Fueggle SN, Bellgrove MA, Fox AM. The error-related negativity (ERN) is an electrophysiological marker of motor impulsiveness on the Barratt Impulsiveness Scale (BIS-11) during adolescence. Developmental Cognitive Neuroscience. 2018. 30: 77-86

Titlic M, Mise NI, Pintaric I, Rogosic V, Vanjaka-Rogosic L, Mihalj M, Jurinovic P, Katic AC, Andjelinovic M. The Event-related Potential P300 in Patients with Migraine. Acta Inform Med. 2015. 23: 339-342.

Wamain Y, Gabrielli F, Coello Y. EEG $\mu$ rhythm in virtual reality reveals that motor coding of visual objects in peripersonal space is task dependent, Cortex. 2016. 74: 20-30.

Wang Y, Sokhadze EM, El-Baz AS, Li X, Sears L, Casanova MF, Tasman A. Relative Power of Specific EEG Bands and Their Ratios during Neurofeedback Training in Children with Autism Spectrum Disorder. Front Hum Neurosci. 2015. 9: 723.

Weschke S, Niedeggen M. Target and Non-Target Processing during Oddball and Cyberball: A Comparative Event-Related Potential Study. PLoS One. 2016. 11.

Yuezhi L, Wuyi W, Tiebang L, Lijie R, Yunfei Z, Changhong Y, Xingda Q, Yong H. Source analysis of P3a and P3b components to investigate interaction of depression and anxiety in attentional systems. Scientific Reports. 2015. 5: 17138.

Zhenhe Z, Cui L, Hongmei Z. An error-related negativity potential investigation of response monitoring function in individuals with Internet addiction disorder. Front Behav Neurosci. 2013. 7: 131

Zhu X, Wu H, Yang S, Gu R. The influence of self-construal type on outcome evaluation: Evidence from event-related potentials. Int J Psychophysiol. 2017. 112: 64-69.

https://doi.org/10.15616/BSL.2019.25.2.139

Cite this article as: Hyun KY, Lee GH. Analysis of Change of Event Related Potential in Escape Test using Virtual Reality Technology. Biomedical Science Letters. 2019. 25: 139-148. 